\title{
'Empowerment' in the Era of 'Resilience-Building': Gendered Participation in Community-Based (Disaster) Risk Management in the Philippines
}

\section{Acknowledgements}

The $\mathrm{PhD}$ research on which this article is based was generously supported by an Economic and Social Research Council Postgraduate Award (ES/J500070/1) through the Department of Geography and Environment, London School of Economics and Political Science, for a thesis provisionally entitled: 'Risk, Resilience and Responsibilisation: Gendered Participation and Empowerment in the Slums of Metro Cebu, the Philippines'. The author would like to thank Sylvia Chant, the IDPR editors and two anonymous referees for their helpful comments on earlier drafts, as well as FORGE, Regina Yoma, and the many people in the Philippines whose time and support made this study possible.

\section{Author Bio}

Jordana Ramalho is a $\mathrm{PhD}$ Candidate in Human Geography and Urban Studies at the London School of Economics and Political Science, Houghton Street, London, WC2A 2AE, UK (e-mail: j.r.ramalho@1se.ac.uk). Her research interests include the geographies of gender, socially inclusive development, participatory governance, poverty, and urban political ecology.

\footnotetext{
Abstract

As the economic, social and environmental impacts of climate change become increasingly apparent in the Philippines, community-based approaches to disaster risk reduction and management (DRRM) have become the new orthodoxy, framed by narratives of participation, empowerment and resilience. Among the urban poor, state-endorsed risk reduction interventions are often facilitated via homeowner associations, with women serving as critical drivers of grassroots action within these spaces. This article interrogates whether these community-based 
mobilisations are serving to address or exacerbate gendered inequalities that underpin vulnerabilities to risk. I argue that grassroots 'resilience-building' and community-based DRRM are decidedly gendered in practice, and reveal complex dynamics whereby participation in these activities is reinforcing gendered inequalities and power differentials while simultaneously facilitating positive personal transformations among female members. The findings of this study reinforce the importance of understanding the socio-spatial manifestations of gender roles, power and agency to the development of inclusive DRRM and 'resilience-building' strategies.

\section{Introduction}

In the Philippines, the visible and as yet unseen impacts of climate change are exacerbating conditions of precarity among low-income informal settlers, who are often most exposed and least able to protect themselves from the adverse and compounding effects of extreme weather events. Despite their residing on land typically deemed undesirable by those with alternatives, rapid urbanisation coupled with severe land shortages and a competitive commercial and property development market, have left many of these communities fighting for their right to remain in the city and made land tenure one of the most pressing concerns facing the urban poor across the archipelago. In an effort to mitigate and resist the various socio-political and environmental hazards that threaten their well-being and urban residence, a growing number of informal settlers are forming homeowner associations; many encouraged to do so by the government or nongovernmental organisations (NGOs) as a prerequisite to any dialogue or negotiations involving the state. While not necessarily a new feature of the urban political landscape, these organisations are proving increasingly pivotal to risk management in urban poor communities.

Propelled largely through acts of volunteerism, personal initiative and sacrifice, women are the driving force behind much of this activity, dominating in numbers if not always in authority. With popular concern for creating 'resilient cities' increasing globally, homeowner associations 
are simultaneously being harnessed to serve municipal disaster risk reduction and management (DRRM) agendas under the label of 'bottom-up participation' which is actively promoted in preference to traditional 'top-down', centralised DRRM and development. Given that women constitute such a high proportion of the 'volunteers' on which these initiatives depend, a closer appraisal of the gendered consequences arising from participation in these spaces is crucial to ensuring that contemporary urban development and 'resilience-building' are as 'inclusive' and 'empowering' as they claim (or aspire) to be. Alternatively they may reflect what Chant (2008, 182) has termed a 'feminisation of responsibility and/or obligation', where the perpetuation of traditional gender roles and female-oriented norms of altruism by development programmes leave poor women largely responsible for meeting poverty alleviation targets. As observed by Bradshaw (2013, 155; 2015, S70), similar dynamics may also be transferring to the realm of disaster management, where women's inclusion in DRRM, especially post-disaster, seems equally driven by instrumentalist motives of efficiency over equity, leaving them bearing the brunt of the burdens for 'building-back better'.

Drawing on the testimonies of informal settler homeowner association members in Metro Cebu, this article interrogates the gendered implications associated with so-called 'bottom-up' risk reduction, reflecting on the potentials and pitfalls of participating in these community-based mobilisations. Mindful of Chant's (2008) and Bradshaw's (2013; 2015) cautions, I evaluate the nature and terms of individual participation in homeowner associations, paying particular attention to the effects these movements are having on personal and collective labour burdens, agency and consciousness, as well as on wider socio-political structures and hierarchies underpinning (gendered) vulnerabilities to risks. These findings complement the work of many other scholars critical of the packaging and promotion of localism and citizen engagement as a panacea for 'efficient' and 'empowering' development (Beard and Cartmill, 2007; Cornwall, 2003; Dill, 2009; Mohan and Stokke, 2000), and also build on existing literature pertaining to community-based 
disaster risk management (CBDRM) and gender in the Philippines (Allen, 2006; Delica, 1998; Gaillard, 2015). The analysis centres on the perspectives and experiences of the urban poor themselves, and the challenges, meaning and value derived from their participation in these organisations.

Beginning with a brief conceptual overview of participation, empowerment and their relevance to contemporary debates in disaster resilience, I offer some context on the gender, development and disaster landscape in the Philippines to frame the ensuing analysis. I proceed to detail the role of homeowner associations in informal settlements, and specifically their risk management function, analysing the individual motivations driving participation, as well as the socio-spatial manifestations of gender roles, power and agency within, and extending from, 'bottom-up' interventions working in service of DRRM. Identifying a set of seemingly contradictory dynamics which simultaneously enable and constrain potential for transformative gendered empowerment, I argue that traditional gender ideologies and associated labour inequalities are being inadvertently perpetuated through loosely mandated bayanihan ${ }^{1}$ activities, which are themselves bolstered by civic attempts to govern through responsibilisation. However participation in homeowner associations also appears to be facilitating meaningful (if unintended) transformations at the scale of the individual, with effects that are extending to the realm of the household and beyond.

Although homeowner associations do not self-identify as feminist, nor are they publicly recognised as women's movements or having a particular concern for women's interests per se, this article maintains that issues of female empowerment are fundamentally entangled in the

\footnotetext{
${ }^{1}$ A Tagalog term denoting the spirit of collective action and volunteerism, and seen as a core feature of Filipino cultural identity.
} 
activities and efficacies of these institutions, and therein must be acknowledged and considered by civil society and the state alike, particularly as they relate to CBDRM and 'resilience-building' endeavours. The findings presented are based on ethnographic fieldwork conducted in 2016 and 2017 across five informal settlements categorised as 'danger zones' in Cebu City and Mandaue City. All informal settler respondents expressed a personal interest to participate in the study and are members of homeowner associations affiliated with FORGE (the Fellowship for Organising Endeavours); a local NGO that offers support and advocates for the rights and wellbeing of the urban poor and other marginalised communities in Metro Cebu. Data collection included in-depth photo-voice interviews and life story narratives with 44 informal settlers (66 per cent female), and preliminary focus group discussions involving 61 informal settlers (60 per cent female), 22 of whom also participated in the one-to-one interviews. Key themes of discussion elicited from life story narratives included their motivations for joining and engagement in their homeowner association, experiences of risks and disasters, and hopes and dreams for the future.

\section{Problematising participation, empowerment, and resilience}

Participation has established itself as an orthodoxy and assumed marker of good practice within the development sector and beyond. Framed as an alternative to externally imposed, expertoriented development prescriptions which treat the poor as passive recipients, 'bottom-up' participatory approaches view those on the margins as valuable actors and repositories of knowledge, whose active contribution can greatly improve the relevance, efficiency and sustainability of development projects (Cooke and Kothari, 2001, 5). Critical to the systematic endorsement of this paradigm shift from 'top-down' to 'bottom-up' are claims of 'empowerment' (Henkel and Stirrat, 2001, 171; Hickey and Mohan, 2005; Holland et al., 2015); a presumed outcome secured through the inclusion and participation of 'beneficiaries'. These purported empowering benefits extend to the realm of DRRM, where citizen participation and community 
engagement are increasingly promoted as crucial to hazard mitigation, vulnerability reduction and 'resilience-building' (Fernandez et al., 2012).

One of the earliest advocates of CBDRM, Maskrey $(1989,35,44)$ argues that 'reducing vulnerability must involve empowering people, if it is to be truly effective'; a process that he contends 'involves shifting the communities' position from passive 'objects' to active 'subjects' who are enabled to voice their needs, negotiate resources and support from the state and civil society and direct these partnerships to facilitate local risk management. Chambers $(1994,1-2)$ echoes this perspective, identifying 'a transfer of power from "uppers" - people, institutions and disciplines which have been dominant, to "lowers" - people, institutions and disciplines which have been subordinate', as integral to participatory processes. In the absence of this reversal of power relations, he contends that labels of participation are nothing more than 'cosmetic' or 'coopting' efforts to secure public buy-in for low-cost projects delivered using local labour and resources with minimum outside assistance.

However the power relations and binary distinctions between 'uppers' and 'lowers' or state and community are often more blurred and complex than these assertion would imply, and as Cornwall $(2002,4)$ has argued persuasively, participation is neither neutral nor morally and inherently 'good' or 'efficient' in serving the needs of those 'participating'. Rather, these spaces are fraught with contestation and power dynamics that operate within and across scales, and must also be understood and evaluated in relation to the context and means through which they were created (Gaventa, 2002, 7). Following this line, Cornwall distinguishes between 'invited spaces' which are created or legitimised within formal, state-sanctioned frameworks, and 'popular' or 'invented' spaces (Miraftab, 2004, 1) that are produced through initiative and collective action 'from below' and which directly challenge 'the status quo in the hope of larger societal change and resistance to the dominant power relations'. Furthermore, the precise meaning and manner of 'doing' empowerment remains a point of debate amongst scholars and practitioners alike, and akin 
to its partner concept 'participation', its inherently political nature means that the term is frequently deployed by different actors to serve agendas that may actually reinforce rather than address the power differentials underpinning poverty and vulnerability (Cornwall, 2003; Dill, 2009; Rigon, 2014).

Among the most prominent and contested applications of the term 'empowerment' has been in the context of gender equality and women's rights. For Kabeer $(1999,435)$, empowerment constitutes 'the process by which those who have been denied the ability to make strategic life choices acquire such an ability.' In this framing, considerations of women's empowerment cannot be divorced from power relations, and any claims of empowerment must equally evidence transformations in 'the structures of constraint' that perpetuate gender inequalities; changes that may occur at individual, institutional, or wider socio-structural scales (Kabeer, 2001, 46). Institutional interpretations of gender empowerment, conversely, remain dominated by a narrow focus on labour force participation and economic advancement, with female participation broadly promoted as 'smart economics' and the solution to gendered disenfranchisement. Not only does this oversimplify complex issues, but it shifts responsibility (Chant, 2016) away from the 'structures of constraint', eviscerating both terms of any political bite, while serving instrumentalist objectives that make 'women work for development, rather than making development work for their equality and empowerment' (Cornwall and Rivas, 2015, 396-8) .

These debates hold particular relevance to notions of 'resilience-building'; a newer addition to the growing list of contemporary buzzwords pervading the fields of development and disaster management. Conceptualised as both an outcome and a process (Manyena, 2006, 436-9), resilience broadly pertains to the capacity of a system or community to resist, absorb, and recover from exposure to shocks or hazards (Barrett and Constas, 2014). However a consensus on what resilience means in practice for different stakeholders, how it is best achieved, and who is, and/or should be responsible for it has yet to be reached. In line with this ambiguity, the concept has met 
critiques for neglecting to consider hierarchies of power and inequality as they affect different groups and individuals likely to be implicated in these processes (MacKinnon and Derickson, 2012; Swyngedouw and Heynen, 2003). Many scholars have also highlighted its marked parallels with neoliberal logics of governmentality, with rationalities of self-moderation and individual responsibilisation enabling states to govern their subjects from afar (Joseph, 2013; Welsh, 2014). In the context of CBDRM and 'resilience-building' aspirations, Chant (2008) and Bradshaw's (2013; 2015) critical contributions outlined in the introduction offer a useful lens for interrogating the terms of inclusion and impacts of these 'participatory' projects on the women and men involved. Such appraisals must however be rooted in an understanding of gender relations, development and disaster management in the Philippines, a point I turn to now.

\section{Gender and development in the Philippines: paradoxes of empowerment}

The Philippines carries the reputation for being the most gender equitable country in the Asia and Pacific region and the seventh most gender equitable nation worldwide according to the Global Gender Gap Index (GGGI), having maintained its position in top ten list since the measure began in 2006. Areas of celebrated 'female advantage' in this lower-middle income nation include educational attainment, female representation among professional and technical workers, and gendered life expectancy (WEF, 2016), although the extent to which the latter constitutes an 'achievement' is questionable given women's biological 'advantage' in this regard. Female labour force participation is among the highest in the region, extending to the realm of politics, as seen in the election of two female presidents, two female vice presidents and numerous female senators into office. This said, gender gaps in employment and political empowerment remain prominent, with traditional gender stereotypes and overt practices of discrimination serving to stifle women's entry into the labour market while simultaneously constraining their ability to secure decent work (Chant and McIlwaine, 1995). Such gender biases appear to be withstanding the test of time, as 
evidenced by enduring sex-selectivity in traditionally male- or female-oriented sectors, persistent gender pay differentials in certain occupations, and the higher proportion of women than men engaged in vulnerable employment (Albert and Vizmanos, 2017). Consequently, many women have resorted to working abroad, constituting 51 per cent of overseas foreign workers who collectively contributed 180.3 billion pesos in remittances (equivalent to USD 3.53 billion or roughly 10 per cent of GDP) in 2015 (PSA, 2016).

Evidence of the continuing legacy of a 'feminisation of labour'? in the Philippines is further apparent in the 2016 Gender Statistics on Labour and Employment Report (PSA and ICF International, 2014), which shows higher rates of male underemployment and marginally longer hours worked by women than men in paid employment. Gendered discrepancies in economic participation, opportunity and income are even more pronounced among low-income groups, with women in this demographic typically less educated and thus consigned to working in the informal economy where salaries are lower and less reliable, and regulatory avenues for challenging discrimination largely absent. Time poverty differentials are also discernibly greater among the poor, where the cumulative effects of income and infrastructure inadequacies create a 'reproductive tax burden' (Palmer, 1992) requiring women to invest more time in household chores and unpaid carework (Chant, 2014).

While the Philippines has made commendable efforts to establish a legal and institutional framework that is considerate of women's interests, in the context of reproductive rights, the situation remains wanting. Contraception has only recently featured in public health policy, and both abortion and divorce remain illegal. Maternal mortality levels are also insalubriously high at

\footnotetext{
${ }^{2}$ A term referring to rising levels of female labour force participation emerging alongside a shift towards sectors traditionally associated with women that are themselves typified by informal employment arrangements, low salaries and poor working conditions (Chant, 2014).
} 
114 deaths per 100,000 births; significantly higher than the maternal mortality ratio (MMR) of 59 deaths per 100,000 averaged in the East Asia and Pacific region (World Bank, 2015) and the global MMR target of no more than 52 deaths. Furthermore, according to the 2013 Philippines National Demographic and Health Survey (PSA and ICF International, 2014, 13), one in five women reported experiencing physical violence since the age of 15 , with later research also finding that ten per cent of female respondents had experienced spousal physical or sexual violence in the twelve months preceding the survey (World Bank, 2014, 40). Failures to amend other legislation, including the Family Code of 1988 which stipulates the subordinate status of women in relation to conjugal property disagreements and cases of adultery, have also served to undermine judicial efforts in advancing gender equality (Parreñas, 2003).

By neglecting to incorporate these critically important issues of bodily integrity, agency, independence and choice into their framework (see Eerdewijk et al., 2017), gender equality and empowerment measures such as the GGGI present a misleading picture of gendered disadvantage and are especially unrepresentative of the differing realities across socio-economic groups, in a country where more than one-fifth of the population is estimated to be living in poverty (PSA, 2015). Given the unrelenting dependence of the national economy and individual households on the 'feminisation of labour' in its many facets, in a context of already feminised (and possibly feminising) CBDRM initiatives, the extent to which women's participation in these multiple spheres of activity is prompting a redistribution of labour within the household becomes paramount to considerations of 'empowerment' and 'resilience-building'. An awareness for how female agency and initiative is construed by the women themselves, as well as by the wider community, is also integral to this analysis. 


\section{Gender and DRRM}

Despite the visible and active presence of women in Filipino CBDRM, state level discourse continues to frame them first and foremost as victims. For example, the Philippine DRRM Act of 2010 identifies women as 'vulnerable and marginalised' alongside the elderly, ethnic minorities and people with disabilities (Congress of the Philippines, 2010, 12, 24). Rather worryingly, women's access to gender specific support and assistance during and post-disasters appears to be predicated around motherhood, as depicted in the statement encouraging local governments 'to create a special place where internally-displaced mothers can find help with breastfeeding, feed and care for their babies and give support to each other'. While provisions for breast-feeding mothers are important and welcome, the wider effects of unequal care burdens, gendered divisions of labour, violence and insecurity on women's (and men's) health and wellbeing during and postdisaster appear to be subsumed by this narrow focus.

Surprisingly, given the notability of the Philippines for mainstreaming gender into DRRM, bar the generic affirmations about including marginalised groups and strengthening their DRRM capacities, this is also the only area where gender (or more accurately female) specific considerations are noted explicitly. Similarly, in the 2009 Climate Change Act, the only appearance of gender in any guise is in the call for special attention to 'be given to ensure equal and equitable protection of the poor, women, children and other vulnerable and disadvantaged sectors' (Climate Change Commission, 2010, 5). Statements of recognition that disasters and climate change have differentiated impacts on women and men feature across both documents, as does the need for creating inclusive 'participative' frameworks, however there is no mention of the vital role women play in CBDRM, or any acknowledgement of their frequent exclusion (especially of poor women) in post-disaster planning and decision-making processes.

One possible and welcome exception to this pattern is arguably the Magna Carta of Women, published a year before the DRRM Act of 2010, which identifies the vulnerability of 11 
women and girls to disasters as a 'rights-based' issue, highlighting gender-based violence, reproductive, mental, and physical health, access to information and livelihood support as critical areas affecting women during and post-disaster. It also offers more nuanced guidance for mainstreaming gender into DRRM practice, including the collection and use of sex-disaggregated data and reproductive health indicators in planning humanitarian responses, proactively adopting measures to prevent sexual violence in evacuation centres, and ensuring the active involvement of women in camp committees and decision-making processes (PCW, 2010, 53-4). Given the quality of this document, it is unfortunate but perhaps telling that the language and best practice offered did not transfer to these other pieces of legislation, nor was any reference even made to the Magna Carta. It appears that in the Philippines as elsewhere, the mainstreaming of 'gender' into DRRM remains largely premised around biologically deterministic stereotypes, ignoring the multiple subjectivities inherent to personal experiences of insecurity, deprivation and calamity, and failing to confront issues of power and powerlessness underpinning vulnerability which are equally critical to the dynamics and outcomes of 'participatory' processes (Cornwall, 2003).

With this as context, I now turn my attention to analyse participation in homeowner associations from the perspectives of women and men living in informal settlements, who, in the context of Metro Cebu, are among the primary 'objects' of municipal risk management and social development interventions. In addition to the various environmental and anthropogenic risks associated with absent or inadequate provision of basic infrastructure and social services, these communities are especially vulnerable to landslides and storm surge (in hilly and coastal areas respectively), and floods and fires more ubiquitously. While the destruction incurred by some of these events may earn them the title of 'disaster', attracting with it some level of humanitarian or state assistance, the majority pass unnoticed in the public eye, despite the deleterious losses and disruption experienced by those affected. 


\section{Risk, gender and participation}

Homeowner associations are mandated through the 2009 Magna Carta for Homeowners and Homeowner Associations and once registered, become the delegated authority on various local governance matters. In informal settlements, this includes everything from sourcing affordable water and electricity connections through to negotiating public investments for roads, sanitation and public transportation links. Homeowner associations also take the lead in identifying affordable relocation sites and advocating for the broader interests of their communities in circumstances of eviction. Supported by FORGE, many have also set up Emergency Response Teams owing to the geographic, environmental and infrastructural conditions that inhibit rapid response from state services in times of crisis, as well as Family Development Committees offering support and intervention around cases of domestic violence.

In all of their capacities, these institutions act as conduits of information exchange between outside parties and local residents, and actively contribute to improving the social welfare of the urban poor in a context of limited state capacities. In this regard, while homeowner associations can be classified as 'invited spaces' (Cornwall, 2002) that are endorsed by the state and which facilitate their ability to govern urban poor communities, they also constitute an important medium through which informal setters are able to voice their interests, make claims on public resources and contest efforts to displace them without adequate compensation or provisions for relocation. The diverse portfolio of homeowner association activities are all in one form or another working to address, reduce or manage the various circumstances of insecurity affecting their members. The majority of these risks are spatially associated with the home and its surrounding environment, meaning that they are also gendered in several respects, with direct implications for participatory dynamics. 


\section{Gendered risk and feminised participation}

Homeowner associations consist of members and officers elected from the membership base to undertake different roles relevant to each association's mandates and priorities. Among the officers, the Board of Trustees oversees the functioning of the association, proposing measures and discharging duties to the Executive Committee (president, vice president, secretary, treasurer and auditor), who lead on the day-to-day running of the association and implementation of initiatives (see Figure 1). At the time of field research, in four of the five study sites, Executive Committee officials were almost all women, though interestingly, in the outlier, all bar one of these officers (the secretary) were men. Across all associations, male office-holding was more prominent in the Board of Trustees, though in several associations, women were still the majority. The dynamics and factors contributing to the gendered differences observed between these leadership bodies are complex, and warrant an in-depth analysis deserving of its own article. In the absence of this however, what is clear is that an array of social and political forces are influencing the democratic processes operating within these participatory spaces.

\section{Figure 1. Homeowners Association Structure and Duties}

\section{**INSERT FIGURE 1 HERE**}

Traditional gendered dynamics and hierarchies may be reflected in the higher proportion of men participating in the Board of Trustees compared with the Executive Committee; a less labour intensive role, but one with notable clout and authority in its de jure status as the decisionmaking body of the association. Women conversely, make up the majority of officers who are putting in the time and effort to carry out the bulk of unremunerated associational activities. Given that in practice, the Board typically relies on the ideas and guidance from the president and vice 
president, the predominantly female Executive Committees are also the de facto drivers of decision-making. Furthermore, in all five communities including that with a majority male group of officers, women are the most visible and regular participants at community meetings, seminars and events. I argue that gender roles, norms and perceptions are contributing to the feminised character of rank-and file participation, as depicted in my analysis of respondent testimonies below.

Overwhelmingly, across all five study sites, land tenure insecurity was the primary reason motivating individuals to establish or join a homeowner association, as respondents felt that in doing so, they would not be easily displaced without some kind of relocation support or compensation. All of the respondents acknowledged that they did not own the land they were on, with several referring to themselves as 'squatters', and more than demolition, expressed a fear of being evicted without the offer of a relocation site. This was even the case for those living in a publicly-owned resettlement area, as recounted by one female resident: 'We cannot pay the money back to the government for the land and if we cannot pay, we might be demolished. I am not sure what will happen.' $3 *$

Although the threat of eviction and associated struggles of economic and livelihood insecurity were routinely expressed by both male and female respondents, women, seemed especially preoccupied by these issues, or at a minimum, vocalised their worries in the interviews more than men. These gender differences were most acutely apparent in the focus group

\footnotetext{
${ }^{3}$ Quotations marked with an asterisk (*) are excerpts from interviews with informal settler homeowner association members that were translated from Cebuano into English by my research assistant following the interview process. All names have been changed to preserve anonymity.
} 
discussions, when participants were asked to rate on a scale from one to ten how sufficient their household resources were in meeting their households' daily needs (one being completely insufficient, ten being fully sufficient). Across all communities, bar a few individual exceptions, female respondents ranked themselves lower on the scale than their male peers, ${ }^{4}$ and often considerably lower, even in cases where respondents were drawn from the same household. These differences likely relate to women's heightened feelings (and realities) of livelihood fragility and financial dependence compared with their male counterparts. As relayed by mother of one, Anna (42): 'There is a difference between me and my husband because I cannot work like him in the port area. ... It is hard for me to find work. ... Most of the work opportunities for men is based on their strength, and so we have different opportunities.'*

Subtle differences in gendered perceptions also emerged in discussions about risks emanating from infrastructural deficiencies, including waste disposal and consequent flooding, electricity, water, and road and transportation links. Here women's concerns tended to revolve around the health, safety and wellbeing of their children and partners associated with dengue, waterborne illnesses, road accidents, and exposure to violence, whereas men expressed particular concern over the impacts of infrastructure inadequacies on their livelihoods and income-generating potential. Gendered mobilities as an extension of gendered roles and identities seem a reasonable explanation for these differences in how women and men speak about and internalise risk and insecurity. With women typically more confined to the domestic realm in their reproductive and productive roles, and whose gendered identities are often tied to the home, their interests in issues

\footnotetext{
${ }^{4}$ The female average was 3.37 compared to 5.87 for men. Of the 37 female focus group participants, only four women ranked their household assets above six (two as seven and two as ten). Conversely, among the 24 male participants, eleven ranked their household assets above five, seven of whom recorded it as a ten on the scale.
} 
that threaten or affect this environment is perhaps of little surprise. However these gendered differences in perceptions of (and exposure to) risk are intrinsically connected to participation in homeowner associations and their associated risk management activities; a process most acutely apparent in the context of bayanihan.

\section{Bayanihan}

Across many parts of Southeast Asia, acts of mutual assistance and collective action constitute a key feature of cultural identity and nationhood. In the Philippines, this tradition is enshrined in the concept of bayanihan, born from the Tagalog word bayan meaning people, village or nation, which encompasses various acts of self-help organising at the neighbourhood level (Bankoff, 2007, 331). Women have long been prominent actors in these networks of collective mobilisation and social capital, which have in turn been fundamental in the more recent establishment of communitybased social assistance organisations. Among the urban poor of Metro Cebu, examples of bayanihan or tinabangay as it is sometimes called in Cebuano, include communal efforts to gather and clear garbage from their neighbourhood and local waterways, building and repairing public infrastructure such as roads, toilets and chapels, and helping neighbours make home improvements.

According to the officers interviewed, participation in monthly bayanihan is a responsibility of all homeowner association members, with those unable to attend expected to contribute financially to snacks or materials in lieu of labour. However as is often the case, collective duties are rarely shared in practice, and, according to my observations, which were further substantiated by respondent testimonies, women are typically the main 'volunteers' in these mandated monthly bayanihan initiatives. Feminised participation is especially prominent in wasteclearing and management initiatives which are both the most common, and arguably among the least appealing or revered bayanihan activities. Interestingly however, bayanihan oriented around 
more stereotypically male domains, such as road and housing construction or infrastructure maintenance, notably attract more male participants, though women are still present as labourers and in the background doing the cooking. Carmen (40), a mother of three boys and vice president of her homeowner association, described the situation in her community thus:

With this road construction some would say that the reason there are a lot of men doing it is because women are not capable of doing it but for me, I think it is really possible for us to help. But with cleaning [garbage] it is always women. It is like the men become women [weak] when it comes to cleaning [laughs]. Like they can't do it. But maybe they just don't like cleaning. With bayanihan is important that we help each other out. Because this is not just for one family or two families, but it is for the entire community. Everyone will benefit from it.*

Carmen's testimony indicates that traditional gender norms continue to be an influential force defining the distribution of labour burdens within homeowner associations.

Traditional ideas around gendered roles are also being reinforced by government narratives, with one high ranking local government official who facilitates community seminars telling me that waste 'segregation should start in the kitchen'; inadvertently marking waste management (portrayed as the primary cause of flooding) as women's responsibility. In this light, risk management through bayanihan is reproducing existing gendered power hierarchies based on essentialist stereotypes that designate specific domains and duties to men and women. This extends to the distribution of labour in community-based emergency response teams, where men volunteer in crowd-control and rescuing, but are less engaged in prevention-oriented processes that require more sustained participation outside the immediacy of a calamitous event. In failing to directly acknowledge gendered distributions of labour in the reproductive sphere, CBDRM initiatives are thus contributing to a 'feminisation of responsibility and obligation' as discussed by Chant (2008), and reinforcing rather than redressing stereotypes and divisions of labour that underpin gendered 
vulnerabilities. While bayanihan in the context of homeowner associations typically designates a specific set of interventions such as the waste-clearing and site maintenance activities described above, the spirit of volunteerism inherent to bayanihan extends beyond these initiatives to include the wider management of the associations.

\section{Exploitation or empowerment?}

\section{Sacrifice and Obligation}

Both male and female officers defined their work in the association as an act of volunteerism; one which gave them feelings of personal fulfilment, though in equal measure came with many personal costs. The majority of officers interviewed had been serving their association in one capacity or another for years, and in several cases, had personally instigated the establishment of their organisation. With the efficacy of the association entirely dependent on the initiative, investment and vision of its leaders, individuals who demonstrate commitment and achievements are regularly re-elected, sometimes despite their best efforts to stand down. As relayed by Marcella (33), a married mother of seven who pioneered the establishment of her community's homeowner association when they were threatened with eviction in 2005 and has since been serving in the Executive Committee:

Well it is a very tiring job for me. And I don't have any salary for it, but I wasn't able to do anything about it because people voted for me for the position. I have no choice ... because even though I do a good job of hiding they can find me anywhere. ... I want to resign actually. But ... they will not accept my resignation letter ... so I can’t do anything about it. So I just say so be it, I'll just do whatever is needed. ... In every election they keep on voting for me. Even if I am absent because of different excuses like "oh I have a fever or a stomach ache so I can't attend"... they will just reschedule the meeting so that I 
can attend ... so my husband advised me to just attend because it is a hassle and they will just keep rescheduling the meeting until I attend.*

Marcella's account echoes the tales of many other female officers, and mirrors findings in other studies of cyclical leadership patters among the 'usual suspects' with 'burnout' being a common result (Gaventa, 2004, 13). In fact, several homeowner association members recounted the pressures and difficulties associated with being an officer; a point which made them happy to let others take the lead. In these conversations, the influence of gender norms on perceptions about (and participation in) leadership again featured prominently, though perhaps in a less conventional way than might be expected.

Many of the men I spoke with felt that women were better suited to being officers, as in addition to 'having more free time', women were deemed more literate, more diplomatic and better able to amicably resolve conflicts, all of which were considered integral to these leadership roles. Member and father of two Ninoy (35) said: 'I don't like to be an officer, because it is difficult. It is troublesome because if you are an officer you need to go out to different places all the time and deal with many many problems like the budgeting and also hard-headed people [conflict].'* Another male respondent, Jaco (57) felt similarly:

Well I really don't know how to read and write. But even if I could, I would only want to be a member.... These officers have their own gubot [conflict] with each other. ... I think that most of the men here are just contented to become members. I am not sure [why] ... but they usually decide only to participate as members and allow women to be active and do the actions here in the community.*

These reflections suggest that men may indeed feel less confident about their ability to fill the role, indicating a possible and as yet unacknowledged area for gendered capacity building. In equal measure however, it is also clear that male members are very aware of the extensive time and labour burdens for officers, and are choosing to opt out of these responsibilities, culminating in a 
degree of gendered free-riding as they share in collective benefits accrued through the efforts of (predominantly female) officers.

In mainstream national discourse, the gendered costs and contributions of participating in CBDRM and other 'bottom-up' interventions are grossly under acknowledged, and the notable absence of men compared to women, is neither questioned nor problematised by government, civil society, or even the communities themselves. Instead, this accepted reality is typically dismissed with the explanation that men are 'busy at work', and women are unemployed and have 'lots of extra time' to attend meetings and participate in community activities. However, among my sample of respondents, while it was true that more women were out of work than men, many of the male and female officers were employed in either full or part-time work in both formal and informal sectors, negating time and employability as key explanatory variables for under-participation. Not only does this claim therein fail to hold up to empirical scrutiny, but it also devalues women's volunteerism and unpaid contributions to their households and communities. Furthermore, such assumptions excuse men from partaking in communal activities rather than encouraging their involvement and trying to address barriers to their participation. Given the prominent role of homeowner associations as networks of information exchange on issues pertaining to the security and wellbeing of their communities, it is arguably crucial to identify any obstacles to inclusion that may discourage men from engaging in these spaces, particularly in the context of male-headed single parent households, whose potential isolation from these networks may inadvertently be a source of vulnerability.

\section{Narratives of Empowerment}

On the basis of the analysis of gendered participation in homeowner associations offered so far, it would seem that the cautions proposed by Chant (2008) and Bradshaw $(2013 ; 2015)$ are especially relevant to community organising and associated grassroots risk management interventions among 
urban poor communities in the Philippines, where women's time and labour investments in community affairs seem to far surpass those of their male counterparts. However, a closer analysis of women's personal narratives reveals a somewhat different picture, with women describing their experiences of volunteerism, and specifically their involvement in homeowner associations, using a language of empowerment. Many told me how their participation in these organisations gave them a sense of self-worth, expanded their knowledge, mobility and confidence, and helped them develop skills and build social networks, all of which contributed to a growth in their sense of agency and independence. As described to me by mother of seven and retired officer, Rita (35):

It is not only about wanting to help out in the organisation or with the community. But for me it [the homeowner association] is a very big help, because ... I know about my human rights and learned for myself about what is good for me. Before ... understanding my rights ... I was just scared of people coming to us [and threatening eviction]. And also I really didn't know how to respond ... or what to say to them to defend myself. I was very shy and really didn't want to interact with these people [in government] or have meetings with them, because for me I really felt myself as lower than them so I was embarrassed. ... But now after all these trainings ... all my fears and all my worries were put aside and I was able to defend myself.*

On the back of becoming more active in their homeowner association, several female respondents went on to secure paid employment, some in local government or offshoot livelihood programmes thanks to the skills and contacts they had acquired from volunteering and specifically from FORGE's seminars. Describing herself as a 'plain housewife' before she started volunteering, Mina (40), the president and founder of her homeowner association, now works for the local government, sits on the boards of several urban poor organisations, and is even considering running for a position in the city council. As another indicator of transformative change relating to gender empowerment, the distribution of unpaid labour is now shared in her 
household, contravening traditional gender norms: 'My husband is actually the main cook, I am only the assistant cook. He also washes the dishes and helps with the laundry. He cannot find work so he is a house husband and helps me a lot.'* Mina recounted how when she first became more active in community affairs, her husband was resistant and would get angry with her for coming in late and spending so much time away from home, especially as she was not bringing in a salary: I went through a transformation adjusting my life in this set up. ... [Now] we are partners. My husband is very supportive of all the things that I do. He is very understanding and has patience. ... I often boost his self-esteem because most of the time he has this self-pity. Because here in the Philippines ... it is the husband that is ... the breadwinner but in our case it is the opposite.... What I ... try to get him to understand is that we are a family so we are partners and we must work together. ... [B] efore he didn't understand our situation ... so he would often drink but now he has come to accept the fact.

Similar changes in confidence and consciousness vis-a-vis rights and personal agency were recounted by Linda (39):

Before I joined [the association] ... I was always angry or ... disappointed in my life, but when ... I [started] to volunteer, and to attend these seminars and trainings, there was really a change in me.... One of the greatest differences ... was that I was challenged. I got the advice that even as a mother, I need to be very independent ... That's why even though my husband really didn't want me to join the livelihood programme ... I did it. Because I really want to be independent and earn my own money... I now know that as a woman I have these rights, and even though your husband wants you to do these things, if you don't like it, then you have the choice not to do it.*

Other women told me that upon learning about legislation prohibiting violence against women and children, they stood up to their abusive partners, either by leaving or threatening to put them in jail if the abuse continued. Through the Family Development Committees, women (and men) also 
started collectively intervening in local cases of domestic abuse, providing support to victims and signposting both victims and perpetrators to information and services. These transformative accounts are not to be romanticised and do not reflect everyone's experiences, but equally should not be dismissed as they reveal very tangible and important outcomes for the women and families concerned.

\section{Conclusion}

This article has examined the paradox of participation inherent to 'bottom-up' CBDRM initiatives in urban informal settlements in the Philippines. Identifying homeowner associations as critical vehicles of risk management among the urban poor, it has emphasised the dangers of depicting these spaces and CBDRM activities as politically neutral, uncovering how participation is shaped by existing norms and power relations premised around gendered stereotypes, perceptions of, and vulnerability to different types of risk. These local institutions celebrated as beacons of 'resiliencebuilding' and 'empowerment' may furthermore be inadvertently reinforcing gender dynamics that instrumentalise notions of female selflessness, altruism and sacrifice in service of the collective good and efficiency gains. Not discounting the labour burdens and personal costs associated with participation, women's personal narratives equally reveal these arenas to be significant sites of personal empowerment and transformation; an entry point for them to acquire new skills and knowledge, to grow in confidence, and expand their mobility and social and political networks. These findings reinforce the complex gender dynamics entangled in community-based initiatives, cautioning against essentialist suppositions of participation as either empowering or exploitative. Without attending to the socio-spatial manifestations of gender roles, power and agency within 
these processes in specific localities, CBDRM and resilience-building interventions are unlikely to realise their full transformative potential.

\section{References}

Allen, K. A. (2006), 'Community-based disaster preparedness and climate adaptation: local capacity-building in the Philippines', Disasters, 30(1), 81-101.

Albert, J. R. G. and Vizmanos, J. F. V. (2017), 'Do men and women in the Philippines have equal economic opportunities?', Philippine Institute for Development Studies, Policy Notes, April, Manila, PIDS.

Bankoff, G. (2007), 'Dangers to going it alone: social capital and the origins of community resilience in the Philippines', Continuity and Change, 22(2), 327-55.

Barrett, C. B. and Constas, M. A. (2014), 'Toward a theory of resilience for international development applications', Proceedings of the National Academy of Sciences, 111(40), 14625-30.

Beard, V. A. and Cartmill, R. S. (2007), 'Gender, collective action and participatory development in Indonesia', International Development and Planning Review, 29(2), 185213.

Bradshaw, S. (2013), Gender, development and disasters, Cheltenham, Edward Elgar Publishing.

Bradshaw, S. (2015) 'Engendering development and disasters’, Disasters 39(S1): S54-S75.

Chambers, R. (1994), 'Paradigm shifts and the practice of participatory research and development' (Working Paper No. 2), Brighton: IDS.

Chant, S. (2008), “The "feminisation of poverty"and the "feminisation" of anti-poverty programmes: Room for revision?', The Journal of Development Studies, 44(2), 165-97.

Chant, S. (2014), 'Exploring the "feminisation of poverty" in relation to women's work and 
home-based enterprise in slums of the Global South', International Journal of Gender and Entrepreneurship, 6(3), 296-316.

Chant, S. (2016), 'Women , girls and world poverty: empowerment, equality or essentialism ?', International Development and Planning Review, 38(1), 1-24.

Chant, S. and Mcilwaine, C. (1995), Women of a lesser cost: female labour foreign exchange and Philippine development, London, Pluto Press.

Climate Change Commission (2010), 'National framework strategy on climate change 20102022, http://www.climate.gov.ph/index.php/en/documents/category/27-nfscc (accessed 28 November 2017).

Congress of the Philippines (2010), 'Republic Act 10121: the Philippine Disaster Risk Reduction and Management Act', http://www.senate.gov.ph/republic_acts/ra 10121.pdf (accessed 28 November 2017).

Cooke, B. and Kothari, U. (2001), 'The case for participation as tyranny', in B. Cooke, and U. Kothari, (eds) Participation: The new Tyranny? London, Zed Books, 1-15.

Cornwall, A. (2002), 'Locating citizen participation', IDS Bulletin, 33(2), 49-58.

Cornwall, A. (2003), 'Whose voices? Whose choices? Reflections on gender and participatory development', World Development, 31(8), 1325-42.

Cornwall, A. and Rivas, A.-M. (2015), 'From 'gender equality and 'women's empowerment' to global justice: reclaiming a transformative agenda for gender and development", Third World Quarterly, 36(2), 396-415.

Delica, Z. (1998), 'Balancing vulnerability and capacity: women and children in the Philippines', in E. Enarson and B. Morrow (eds), The gendered terrain of disaster, New York, Praeger, 109-114.

Dill, B. (2009), 'The paradoxes of community-based participation in Dar es Salaam', Development and Change, 40(4), 717-43. 
Eerdewijk, A. Van, Wong, F., Vaast, C., Newton, J., Tyszler, M. and Pennington, A. (2017), White paper: a conceptual model of women and girls' empowerment, Amsterdam, Royal Tropical Institute (KIT).

Fernandez, G., Uy, N. and Shaw, R., (2012), 'Community-based disaster risk management experience of the Philippines', in, G. Fernandez, N. Uy and R. Shaw (eds) Communitybased disaster risk reduction (Community, Environment and Disaster Risk Management, Volume 10), Emerald Group Publishing Limited, 205-31.

Gaillard, J. C. (2015), 'People's response to disasters in the Philippines: vulnerability, capacities, and resilience', Disaster Studies, US, Palgrave Macmillan.

Gaventa, J. (2002), 'Exploring citizenship, participation and accoutnability', IDS Bulletin, 33(2), $1-11$.

Gaventa, J. (2004), 'Representation, community leadership and participation: citizen involvement in neighbourhood renewal and local governance', https://assets.publishing.service.gov.uk/media/57a08cd8ed915d3cfd001664/JGNRU.pdf (accessed 30 October 2017).

Henkel, H. and Stirrat, R. (2001), 'Participation as spiritual duty; empowerment as secular subjection', in Cooke, B. and U. Kothari, (eds), Participation: The New Tyranny, London, Zed Books, 168-84.

Hickey, S. and Mohan, G. (2005), 'Relocating participation within a radical politics of development', Development and Change, 36(2), 237-62.

Holland, J., Jones, S. and Kardan, A. (2015), 'Understanding participation in development : towards a framework', International Development and Planning Review, 37(1), 77-94.

Joseph, J. (2013), 'Resilience as embedded neoliberalism: a governmentality approach', Resilience, 1(1), 38-52.

Kabeer, N. (1999), 'Resources, agency, achievements: reflections on the measurement of 
women's empowerment', Development and Change, 30, 435-64.

Kabeer, N. (2001), 'Reflections on the measurement of women's empowerment', in Sisask, A. (ed.), Discussing women's empowerment: theory and practice, (Sida Studies No.3), 1757.

Mackinnon, D. and Derickson, K. D. (2012), 'From resilience to resourcefulness: A critique of resilience policy and activism', Progress in Human Geography, 37(2), 253-70.

Manyena, S. B. (2006), 'The concept of resilience revisited', Disasters, 30(4), 433-50.

Maskrey, A. (1989), Disaster mitigation: a community based approach, Oxford, Oxfam.

Miraftab, F. (2004), 'Invited and invented spaces of participation: neoliberal citizenship and feminists' expanded notion of politics', Wagadu, 1(Spring), 1-7.

Mohan, G. and Stokke, K. (2000), 'Participatory development and empowerment: the dangers of localism', Third World Quarterly, 21(2), 247-68.

Palmer, I. (1992), 'Gender, equity and economic efficiency in adjustment programmes', in H.

Afshar and C. Dennis (eds), Women and adjustment policies in the third world, Houndmills, Basingstoke, Macmillan, 69-83.

Parreñas, R. S. (2003), 'At the cost of women', Interventions, 5(1), 29-44.

PCW (Philippine Commission on Women) (2010), RA9710 Magna Carta of Women: Implementing rules and regulations, Manila, Philippines, $\mathrm{PCW}$.

PSA (Philippine Statistics Authority) (2015), ‘2015 Full Year Poverty Statistics’ https://psa.gov.ph/content/poverty-incidence-among-filipinos-registered-216-2015-psa (accessed 15 October 2017).

PSA (Philippine Statistics Authority) (2016), '2015 Survey on Overseas Filipinos’ https://psa.gov.ph/content/2015-survey-overseas-filipinos-0 (accessed 21 August 2017). PSA (Philippine Statistics Authority) and ICF International (2014) 2013 Philippines national demographic and health survey: key findings, Manila, Philippines, and Rockville, 
Maryland, USA, PSA and ICF International.

Rigon, A. (2014), 'Building local governance: participation and elite capture in slum-upgrading in Kenya', Development and Change, 45(2), 257-83.

Swyngedouw, E. and Heynen, N. C. (2003), 'Urban political ecology, justice and the politics of scale', Antipode, 35, 898-918.

WEF (The World Economic Forum) (2016), 'The Global Gender Gap Index’, http://reports.weforum.org/global-gender-gap-report-2016/economies/\#economy=PHL (accessed: 21 August 2017).

Welsh, M. (2014), 'Resilience and responsibility: Governing uncertainty in a complex world', Geographical Journal, 180(1), 15-26.

World Bank (2014), Republic of the Philippines gender and development mainstreaming: country gender assessment 2012, Philippines, Washington, D.C, World Bank.

World Bank (2015), 'Maternal mortality ratio (modeled estimate, per 100,000 live births): East Asia and Pacific', http://data.worldbank.org/indicator/SH.STA.MMRT?locations=Z4andyear_high_desc=true (accessed: 21 August 2017). 